\title{
MICROMIXING IN A STATIC MIXER AND AN EMPTY TUBE BY A CHEMICAL METHOD
}

\author{
T. MEYER *, R. DAVID **, A. RENKEN *, J. VILLERMAUX ** \\ - Institut de Génie Chimique, Ecole Polytechnique Fédérale de Lausanne, Suisso \\ * Laboratoire des Sciences du Génie Chimique. Ecole Nationale Supérieure des Industries chimiques, INPL, Nancy, \\ France
}

\begin{abstract}
Micromixing in a static mixer and an empty tube was characterized by the product distribution of fast consecutive competing reactions. As a test reaction, the precipitation of barium sulphate complexed by EDTA in alkaline medium under the influence of an acid was used.

The acid was injected at a point of the reactor into an excess of basic complex. The precipitated $\mathrm{BaSO}_{4}$ is a measure for the degree of segregation which can be characterized by an index $x_{s}$ representing the amount of macrofluid in the partially segregated fluid.

Experiments were carried out in a tubular reactor and in a static mixer in the laminar flow regime $(0.4<\mathrm{R} \theta<$ $300)$ by varying the fluid viscosity $\left(10^{-3}<\mu<26 \cdot 10^{-3} \mathrm{~kg}^{-3} \mathrm{~m}^{-1} \cdot \mathrm{s}^{-1}\right)$ and the flow rate. Furthermore, the characteristic reaction time tr was varied from about 1 to $75 \mathrm{~s}$. Depending on the experimental conditions, the segregation index $X_{s}$ varied from 0.1 to 0.3 for the mixer and from 0.2 to 0.75 for the empty tube. The micromixing time $t_{m}$ was deduced from $X_{s}$ and $t_{r}$. The mixing time $t_{m}$ was found to be about 10 times larger in an empty tube than in the static mixer.
\end{abstract}

\section{Introduction}

Tubular reactors for catalytic as well as non-catalytic reactions in homogeneous liquid phase are of special industrial interest. Polymerization reactions and homogeneously catalysed reactions involving soluble enzymes are examples among a broad range of applications. If media of high viscosity and/or slow reactions are involved, the tubular reactor should be operated in the laminar flow regime. As a consequence, its performance is impaired by the occurrence of unfavourable flow profiles and by convective fluctuations, due to temperature or density gradients. Both effects lead to a broad residence time distribution.

Different means have been used to circumvent the above mentioned problems. Cascading and compartimentation of reactors with or without stirring may be used in addition to tower packings of diverse shapes. A comparison of these devices on the behaviour of tubular reactors with low fluid velocity can be found in Langensiepen, 1980.

Since normal tower packings such as rings and saddles may lead to the formation of dead-zones in the reactor and give rise to high pressure drop for viscous media, regularly arranged rigid packings with high void volume are preferred. In spite of the fact that motionless mixers may have some of the above mentioned disadvantages, they generally improve tubular reactor performance as was proved by two experimental studies: the enzymatic hydrolysis of lactose in whey (Flaschel et al., 1983), and the thermal bulk polymerization of styrene in a pilot plant static mixer (Nguyen et al., 1983). These experiments cover a broad range of viscosities from $\mu=1 \mathrm{mPa}$. in the second one, corresponding to Reynolds numbers between 500 to $10^{-5}$ respectively.

In order to characterize the macroscopic behaviour of the fubular reactor with static mixers, the residence time distribution was determined and evaluated using the axial dispersion model. For the motionless mixer studied (type SMX of Sulzer, Switzerland) with an internal tube diameter of $d_{t}=40 \mathrm{~mm}$, Flaschel et al., 1985, determined a Peclet number of $\mathrm{Pe}=\left(\mathrm{u}^{*} \mathrm{~d}_{t}\right) / \mathrm{D}_{\mathrm{ax}}=3.2$ in the range of $10^{-5}<\mathrm{Re}<10^{2}$. This corresponds to a Bodenstein number of Bo $=$ $\mathrm{u} \cdot \mathrm{L} / \mathrm{D}_{\mathrm{ax}}=80$ for a tube of $1 \mathrm{~m}$ length or to approximately 40 ideal mixing cells per meter using the tanks-in-series model. Metzdorf et al.,1986 confirmed the plug flow behaviour of static mixers at higher Reynolds numbers $(50<$ Re < 1000) and higher tube diameters up to $d_{t}=300 \mathrm{~mm}$.

These results prove that effective macroscopic radial mixing can be achieved using motionless mixers, but they do not yield any information on the quality of microscopic mixing. Mixing on a molecular scale in the reactor becomes important for systems in which the micromixing time and the characteristic time constant of the chemical reaction are of the same order of magnitude. For complex reactions, e.g., co-polymerization, the quality of micromixing will strongly influence the product quality in terms of the mean molecular mass, the molecular mass distribution, the composition of copolymers and the sequence of the monomer units. Theoretical discussions were recently published, for example, by Ranz, 1986, and Fields and Ottino, 1987.

The aims of this contribution are to present a suitable test system for characterizing segregation in lubular reactors operating at low Reynolds numbers and to determine the influence of motionless mixing elements on the micromixing time.

\section{Measurement Prínciples}

Fast consecutive competing reactions are currently used for characterizing segregation in homogeneous systems: 


$$
\begin{array}{ll}
A+B & k_{1} \\
k_{1}>k_{2} & \rightarrow
\end{array} \quad R+B \stackrel{k_{2}}{\rightarrow} S
$$

If a small amount of $B$ is mixed into a large excess of $A$, the intermediate $R$ is immediately formed. Under ideal micromixing conditions, the formation of $S$ is quite negligible owing to the instantaneous dispersion of $B$ and its stoichiometric deficit. If the fluid is partially segregated, $B$ is locally in stoichiometric excess in contact with $R$ which is thus converted to $S$. Therefore, the amount of $S$ formed is a measure of the degree of segregation.

A major advantage is that the system retains a memory of the micromixing process which takes place during the lifetime of segregated eddies. Hence, the amount of $S$ can be determined "off-line" by subsequent analysis of the fluid composition. As proposed by Bourne et al. (1981), the yleld of $\mathbf{S}$ may be considered as a segregation index for the system:

$$
x_{S}=\frac{2 C_{S}}{\left(2 C_{S}+C_{R}\right)}
$$

Besides the well studied azo-coupling of 1-naphthol with diazotised sulphanilic acid (Bourne et al. 1981), the precipitation of barium sulphate (S) from a basic EDTA-complex (A) under the influence of acid (B) has been proposed by Barthole et al.. 1982a. BaSO4 is easily measured after completion of the reaction by sampling and turbidimetry. The kinetics of the test reaction in aqueous solution were studied by Barthole et al, 1982b. The influence of polyethylene glycol (PEG) on the kinetics was studied by Bernaux, 1987.

The reaction scheme may be written as follows:

$$
A+B \stackrel{k 1}{\rightarrow} R+W \quad(3 a) \quad n U+R+2 n B \stackrel{k 2}{\rightarrow} n S+n T
$$

with $A=\left(\mathrm{Ba}^{2+}, \mathrm{Y}^{4-}\right)_{n} \mathrm{OH}^{-} ; \mathrm{B}=\mathrm{H}^{+} ; \mathrm{R}=\left(\mathrm{Ba}^{2+}, \mathrm{Y}^{4-}\right)_{n} ; \mathrm{W}=\mathrm{H}_{2} \mathrm{O} ; \mathrm{U}=\mathrm{SO}_{4}^{2-} ; \mathrm{S}=\mathrm{BaSO}_{4} ; \mathrm{T}^{2}=\mathrm{Y}^{4-}, 2 \mathrm{H}^{+}$

The alkaline solution was prepared using $\mathrm{BaCl}_{2}, \mathrm{NaOH}_{1} \mathrm{Na}_{2} \mathrm{SO}_{4}$ and the sodium salt of EDTA. Then, protons were added in the form of a $0.1 \mathrm{M} \mathrm{HCl}$ solution having a viscosity matching that of the alkaline solution.

The first step is a neutralization reaction and can be considered as instantaneous $\left(k_{1}=1.8 \cdot 10^{8} \mathrm{~m}^{3} \mathrm{~mol}-1 \mathrm{~s}^{-1}\right.$, Eigen and de Maeyer, 1963) compared to the second one, which was found of second order (Barthole et al, 1982b, Bernaux, 1987):

$$
\begin{aligned}
& r_{2}=k_{2} C_{R} C_{U} \\
& \text { with } k_{2}=k_{0} C_{0} 2 / 3 \\
& k_{0}=1.910^{-2} \mathrm{~m}^{5} \mathrm{~mol}^{-5 / 3} \mathrm{~s}^{-1} \quad \text { (water-system) } \quad k_{0}^{\prime}=9.5 \cdot 10^{-2} \mathrm{~m}^{5} \mathrm{~mol}^{-5 / 3} \mathrm{~s}^{-1} \quad \text { (P.E.G., 20\%) }
\end{aligned}
$$

$\mathrm{C}_{0}$ is the concentration of available sites for the crystallization of $\mathrm{BaSO}_{4}$.

$$
\mathrm{C}_{\mathrm{O}}=\mathrm{C}_{\mathrm{SO}}+\frac{1}{2}\left(\mathrm{nC}_{\mathrm{AO}}+\mathrm{CUO}_{\mathrm{O}}-\left|\mathrm{nC}_{\mathrm{AO}}-\mathrm{CUO}_{\mathrm{O}}\right|\right)
$$

A great advantage of the chosen reaction system is the facility to modify the characteristic time (tr) of the second reaction by changing the concentration of $U$ and/or the rate constant $k 2$ by variation of the concentration of available crystallization sites.

$$
t_{r}=\frac{1}{k_{2} \cdot C_{U O}}
$$

According to the overall stoichiometry of the reaction: $A+(2 n+1) B+n U \rightarrow n S+W+n T$

the segregation index $X_{5}$ may be defined from the measured molar production of $\mathrm{BaSO}_{4}$ ( $\mathrm{F}_{\mathrm{s}}$ ) compared to the malar inlet flow of acid (FBo) as:

$$
X S=\frac{(2 n+1)}{n} \frac{F_{S}}{F_{B O}} \quad \text { where } n=\left[\mathrm{Ba}^{2}+\right] /\left[O \mathrm{H}^{-}\right]_{0} \text { and } F_{j}=Q_{j} \cdot C_{j}
$$

\section{Experimental}

The reactor consists of a glass tube with an inner diameter of $d_{t}=39 \mathrm{~mm}$ and a length of $\mathrm{L}=600 \mathrm{~mm}$. The tube can be entirely filled with static mixers of $S M X$ type $\left(d_{m}=38 \mathrm{~mm}, L_{m}=68 \mathrm{~mm}\right)$ from Sulzer, CH, characterized by a hydraulic diameter of $11 \mathrm{~mm}$. The main flow consists of a barium/EDTA solution entering at the bottom of the tubular reactor. The composition is given in Table 1. The Co-reactant B, hydrochloric acid,was injected at different points in the lube or in the static mixer. While changing the flow rate and the concentration, the molar flow ratio, $F_{B o} / F_{A O}$, was held constant and the linear velocity in the outlet section of the cone was held the same as in the tubular reactor to minimize local perturbation in the reactor due to the injection. The ratio of tube area to cone area is 100 and identical to the ratio of the volumetric flow rate through the tube divided by the volumetric flow rate of acid injected through the cone. The characteristic reaction time is varied in the range of $1<t_{r}<75 \mathrm{~s}$. The experimental set-up is shown schematically in Fig. 1. Details of the injection point of the acid are shown in Fig. 2. In most of the experiments, the acid was injected at the center of the tube or mixing element. 

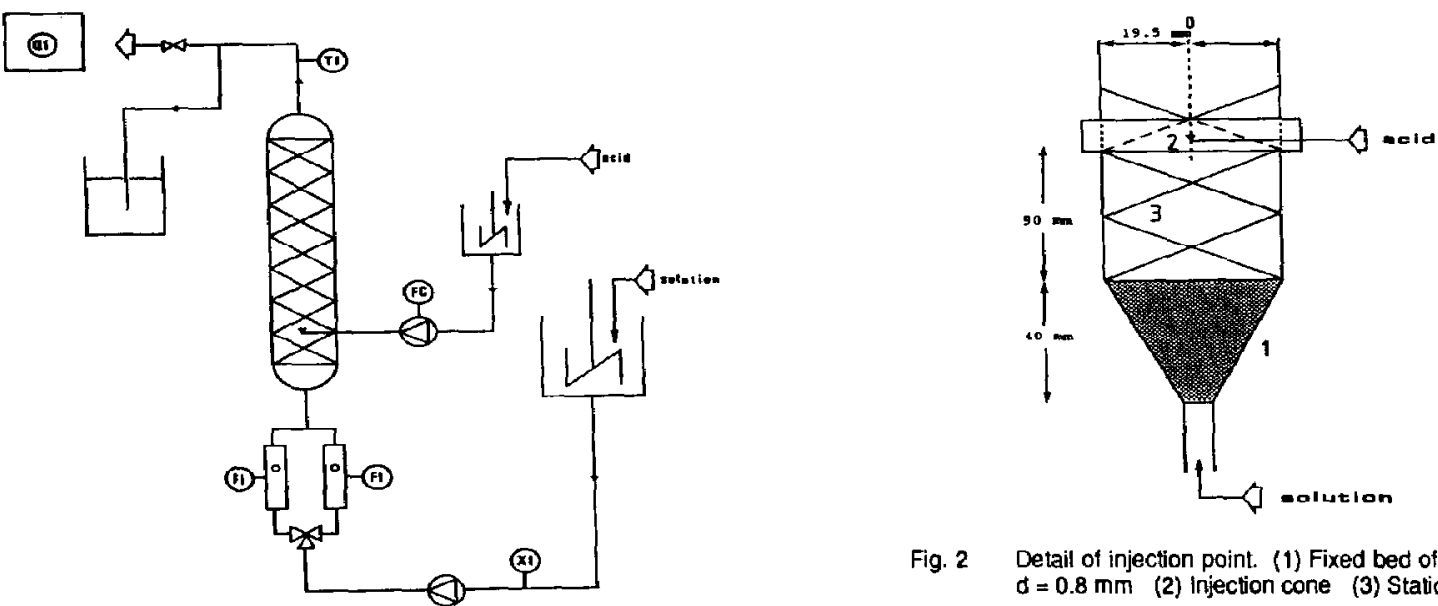

Fig. 1 Experimental set-up reactor with static mixer SMX Sulzer reactor dimension $L=600 \mathrm{~mm}, \alpha_{\mathrm{L}}=39 \mathrm{~mm}$.

The viscosity of the aqueous solutions was modified by addition of Polyethylene Glycol (PEG 20,000). After reaching stationary conditions in the reactor, the concentration of precipitated $\mathrm{BaSO}_{4}$ was determined by spectrophotometry at a wavelength of $650 \mathrm{~nm}$ using a cell of $100 \mathrm{~mm}$ length.

Table 1: Experimental conditions (Inlet-concentrations)

$\begin{array}{llll}{\left[\mathrm{Ba}^{2+}\right]_{0}} & =0.3-2.0 \mathrm{~mol} / \mathrm{m}^{3} & {[B a S O 4]_{0}} & =10^{-3} \mathrm{~mol} / \mathrm{m} \mathrm{m}^{3} \\ \left.[E D T A]_{0}=\mathrm{Y}^{4-}\right]_{0} & =0.3-2.0 \mathrm{~mol} / \mathrm{m}^{3} & {[P E G]} & =20 \% \mathrm{w} / \mathrm{w} \\ {\left[\mathrm{SO}_{4}^{2-}\right]_{0}} & =0.4-2.2 \mathrm{~mol} / \mathrm{m}^{3} & \text { Viscosity } & =26.4 \mathrm{mPa} \cdot \mathrm{s} \\ {\left[\mathrm{H}^{+}\right]_{0}} & =100 \mathrm{~mol} / \mathrm{m}^{3} & \text { Main flow to acid flow ratio: } & 100 \\ {\left[\mathrm{H}^{-}\right]_{0}} & =10 \mathrm{~mol} / \mathrm{m}^{3} & & \end{array}$

\section{Experimental results}

The influence of the Reynolds number on micromixing is shown in Fig. 3. To change the Reynolds number, the flutd viscosity and/or the linear velocity in the lubular reactor was varied. In the given example, the time constant of the reaction is $t_{r}=1 \mathrm{~s}$. Under laminar conditions, the segregation index in the empty tube varied from $X_{s}=70 \%$ (Re $=$ $0.7)$ to $X s=7.5 \%(R e-427)$. The segregation in the static mixer was always smaller under the same conditions and varied from $X_{s}=58 \%(R \theta=0.7)$ to $X_{s}=2.8 \%$ (Re $\left.=427\right)$. For Reynolds numbers higher than $R e=100$, static mixers induce turbulence and the flow is no longer laminar. Since the method used gives information on local micromixing conditions in a streamline starting from the injection point, the segregation index could be determined as a function of radial position in the tube. As shown in Fig. 4, the segregatlon increase is pronounced near the wall for the empty tube, whereas this parameter changes linearly as a function of radius for the static mixer. In both cases, the difference over the radius is about $20 \%$.

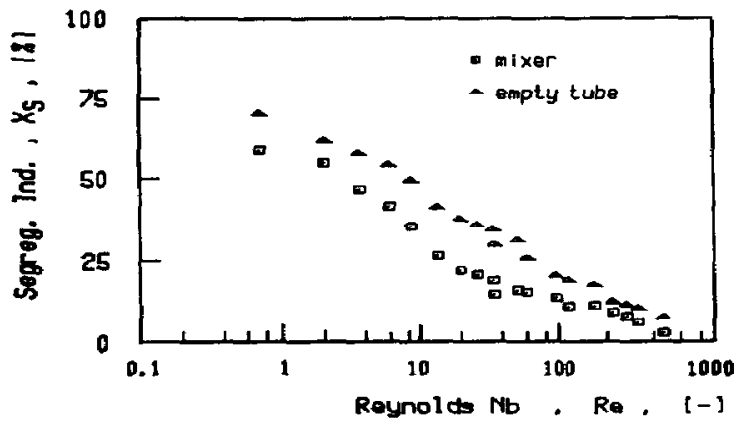

Fig. 3 Segregation index $X_{S} v s$. Reynolds number for an emply bube and static mixer with constant reaction time $t_{\mathrm{t}}=1 \mathrm{~s}$.

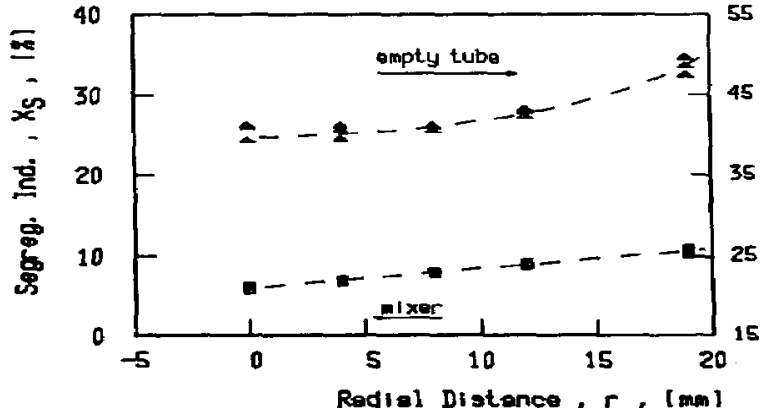

Fig. 4 Segregation index vs, radial distance $r$ for an empty tube and static mixer for $R e=20$ and $t_{r}=1 \mathrm{~s} . r=0$, center of the tube, $r=19$, wall. 
As the characteristic reaction time was held constant in the discussed examples (Fig. 3), the ratio of the space time to the characteristic reaction time varied with the reactor flow rate. Another set of experiments were performed where the Damköhler number was held constant (Fig. 5).

$$
\mathrm{Da}=\tau / \mathrm{tr}_{\mathrm{r}}=\mathrm{k}_{2} \mathrm{C}_{\mathrm{Bo}} \tau=\text { const. }
$$

For the given example, the Damkohler number was fixed to Da $=81$. Under the chosen conditions, the residence time of the fluid in one mixing element was about three times the characteristic reaction time. In other words, the reaction time always corresponded to the time required to pass a tube lenglh of $23 \mathrm{~mm}$ for all Reynolds numbers employed.

The general dependence of the segregation index as a function of the Reynolds number is quite similar for both reactor types. Segregation becomes very important for values smaller than $R_{\theta}=4$. For higher Reynolds numbers, the segregation seems to be independent of the flow rate for constant Damkohler numbers in the laminar regime.

As mentioned. the segregation index is strongly influenced by the reaction rate. With increasing reaction rate, the segregation becomes more and more important in the reactor. This is demonstrated for two different characteristic reaction times in Fig. 6. With increasing reaction time, the reaction rate slows down and mixing effects become less important. This is summarized in Fig. 7 where the segregation index is shown as a function of the Damköhler number for constant hydrodynamic conditions, and a constant Reynolds number. In all experiments, the residence time was held constant and the reaction rate was varied by changing the reactant concentrations $\left(C_{U} U_{0}, n, c_{0}\right)$ The characteristic reaction time ranged between $3 \mathrm{~s}$ and $75 \mathrm{~s}$. In a large domain of Damköhler numbers, the segregation index was found to increase linearly with $\mathrm{Da}$ for both reactor types.

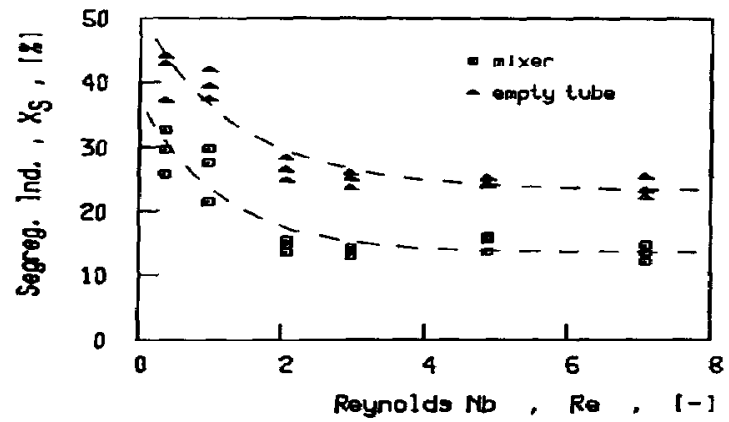

Fig. 5 Segregation index $X_{S}$ vs. Reynolds number for an empty tube and a static mixer for a constant Damköhier number $\mathrm{Da}=81$.

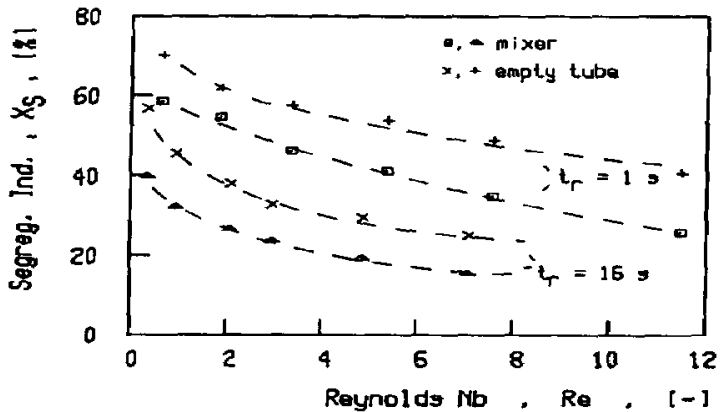

Fig. 6 Effects of reaction time on segregation index vs. Reynolds number for an empty tube and a static mixer.

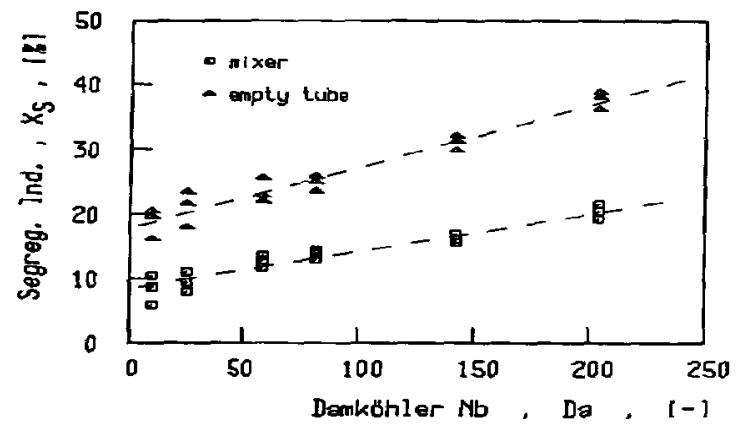

Fig. 7 Segregation index vs. Damkohter number for an empty tube and a static mixer for constant Reynolds number $\mathrm{Re}=3$

\section{Interpretation and discussion}

The micromixing process may be characterized by a time-constant $t m$ depending on the flow conditions and the mixing mechanism. Mixing affects the course of chemical reactions when the characteristic reaction time tr becomes equal to or less than $t_{m}$. If $t_{r} / t_{m}$ is small, the chemical reaction is faster than mixing and microscopic concentration gradients appear and the fluid becomes segregated. To describe the simultaneous diffusion and reaction, the relatively simple "Interaction by Exchange with the Mean" (IEM) Model may be used (Villermaux, 1983, 1986). This model can be interpreted as a lumped version of the distributed parameter Reaction/Diffusion model in which partial derivative equations for transient diffusion with chemical reaction are solved numerically.

Except for some complex mechanisms under stiff conditions, both madels lead to equivalent results. This was checked in the case of consecutive competing reactions. Therefore, the IEM model was preferred for a first interpretation of the experiments, owing to its greater simplicity. 
A very simple way to represent partial segregation in a fluid is to consider it as a mixture of macrofluid (completely segregated fraction $X_{s}$ ) and microfluid (ideally micromixed fraction 1 - $X_{s}$ ). As shown by Villermaux and David, 1983, the ratio of the two fractions is close to that of two characteristic times. On the basis of the IEM model, a simulation was carried out to predict the segregation index and the ratio of the microfluid to the macrofluid fraction $\alpha=$ $\left(1-X_{s}\right) / X_{s}$ for fast consecutive-competing reactions in a plug-flow reactor. These simulations confirm the empirical correlation proposed by Villermaux, 1986.

$$
\alpha=\frac{1-X_{s}}{X_{s}}=a \cdot\left(t_{r} / t_{m}\right)^{b}
$$

This holds provided that $X_{s}$ is not too high. The parameters $a$, and to a lesser extent $b$ are function of the stoichiometric ratio (AVB) and of the ratio of volumetric flowrates of $A$ and $B$ at the reactor inlet (feed point). Application of (7) to experiments at constant Reynolds number and variable Damköhler number leads to

$$
\alpha=a\left(\frac{\tau}{D a t_{m}}\right)^{b}=a\left(\frac{\tau}{t_{m}}{ }^{b} \cdot(D a)^{-b}\right.
$$

A plot of $\log L$ as function of $\log \mathrm{Da}$ is shown in Fig. 8. Linear relationships of the same slope are found for both reactors.

empty tube : $\log \alpha_{e t}=-0.33 \log \mathrm{Da}+1.03$ static mixer $: \log \alpha_{\mathrm{mx}}=-0.33$ in Da +1.39

Supposing $a=$ const in both cases, the ratio of mixing times can be calculated:

$$
\frac{t_{m, e t}}{t_{m}, m x}=12
$$

Therefore, the mixing time in the empty tube is about 10 times longer than in the mixing element SMX used for the described experiment. In the laminar flow regime (Re $\leq 8$ ), this ratio seems to be independent of the Reynolds number. This corresponds to a nearly constant ratio of segregation indices.

$$
\frac{X_{S}, e t}{X_{S} \cdot m x}=1.5 \quad(\operatorname{Re} \leq 8)
$$

Discussing the role of vorticity in micromixing. Bourne, 1984, obtained the following relationship between micromixing time, $t_{m}$, and the rate of local energy dissipation:

$$
t_{m} \sim(v / \varepsilon)^{1 / 2}
$$

The spatial average rate of energy dissipation in the empty tube under laminar flow conditions is given by the HagenPoisseuille-law (eq. 13). For the static mixer SMX used in our experiments, the average rate of energy dissipation can be calculated (Sulzer, 1985) with eq. 14.

$$
\bar{\varepsilon}_{\text {et }}=\frac{Q \cdot \Delta P}{\rho \cdot v}=\frac{512}{\pi^{2}} \cdot \frac{v Q^{2}}{d^{6}}
$$

$$
\vec{\varepsilon}_{m x}=\frac{19200}{\pi^{2}} \cdot \frac{v Q^{2}}{d^{6}}
$$

The ratio of micromixing times estimated assuming homogeneous energy dissipation should therefore be: $t_{\mathrm{m}}, \mathrm{et} / \mathrm{t}_{\mathrm{m}} \mathrm{mx}=$ 6 , which is about a factor 2 smaller than what was observed. The difference may be explained by local variations in the rate of energy dissipation.

Fig. 9 shows the variation of $\mathrm{tm}$ as a function of the Reynolds number. The micromixing time $t \mathrm{~m}$ is found to vary as $R^{-1.5}$. It is difficult to interpret such an exponent in the frame of a purely laminar regime. Further investigations are required thus both to justify this dependency and to obtain the absolute value of $\mathrm{m}$.

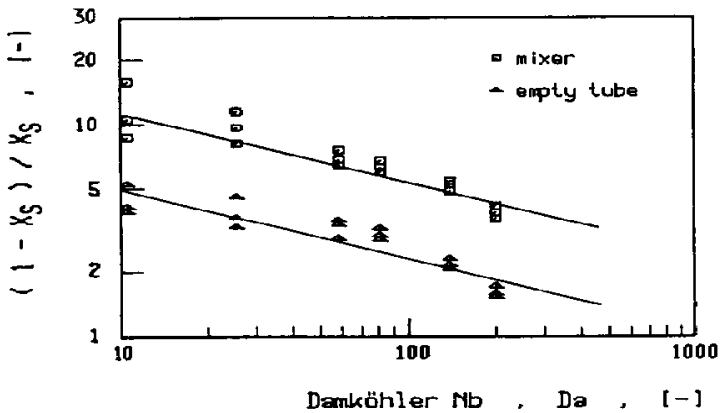

Fig. 8 Empirical model eq. 8 for $R e=3$

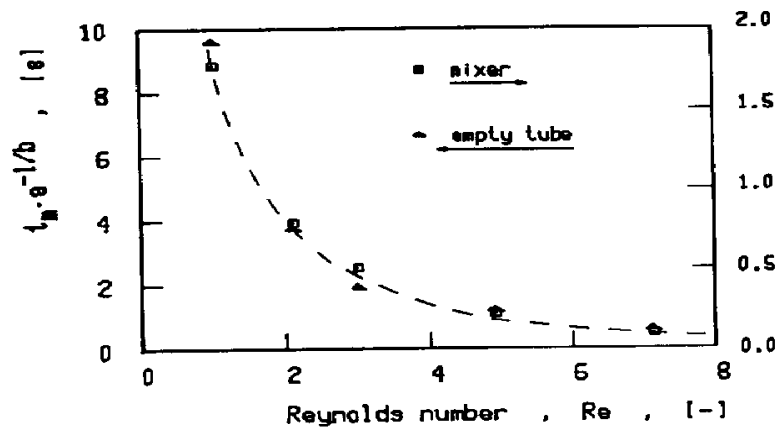

Fig. 9 Relative variation of the mixing time vs. Reynolds number for an empty tube and a static mixer for a constant reaction time $t_{r}=16 \mathrm{~s}$ 


\section{Conclusion}

Besides the macroscopic behaviour of chemical reactors, micromixing is an important determinent of the product distribution in complex chemical reaction systems. The product quality of polymers and co-polymers is strongly dependent on local concentration gradients in the fluid. Tubular reactors represent an interesting alternative to other types of systems for carrying out polymerization. Therefore, a knowledge of micromixing quality is essential. It was shown in the present paper that consecutive-competing reactions could be used to determine the local intensity of micromixing in various kinds of tubular reactors in the laminar flow regime. The selected test-reaction was the precipitation of BasO 4 by an acid from an alkaline EDTA-complex. The characteristic reaction $t$ me could be varied in a wide range (1 $\mathrm{s}<\mathrm{t}_{\mathrm{r}}<75 \mathrm{~s}$ ) to cover the case of relatively slow reactions. Under those conditions, the mixing time in an empty fube was found to be about an order of magnitude larger than in a static mixer. The detailed interpretations of these results will require the application of more elaborate models (David and Villermaux, 1987)

\section{Notation}

\section{Latin Symbols}

c concentration, $\mathrm{mol} / \mathrm{m}^{3}$

d diameter, $m$

D dispersion coefficient, $\mathrm{m}^{2} / \mathrm{s}$

F molar feed

$k$ reaction rate constant, variable dimension

L length, $m$

n stoichiometric coefficient,

Q flow rate, $\mathrm{m}^{3 / \mathrm{s}}$

$r$ reaction rate, mol $m^{-3} s^{-1}$

$t$ time

u superficial velocity, $\mathrm{m} / \mathrm{s}$

\section{Subscript and Abbreviations}

$\begin{array}{ll}\text { et } & \text { empty tube } \\ \text { i } & \text { reaction index } \\ \text { j } & \text { component index } \\ m & \text { mixing } \\ \mathbf{m} \times & \text { motionless mixer } \\ r & \text { reaction }\end{array}$

Dimensionless groups

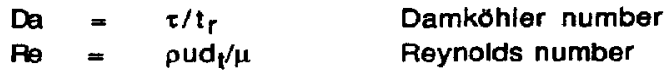

\section{Greek symbols}

$\begin{array}{ll}\rho & \text { density, } \mathrm{kg} / \mathrm{m}^{3} \\ \mu & \text { dynamic viscosity, Pa.s } \\ v & \text { kinematic viscosity, } \mathrm{m}^{2 / \mathrm{s}} \\ \tau & \text { space time, } \mathrm{s}\end{array}$

\section{Literature}

Barthole, J.P., David, R., Villermaux, J., 1982a, A New Chemical Method for the Study of Local Micromixing Conditions in Industrial Stirred Tanks, ACS Symp. Series 196, 545-554

Barthole, J.P., David, R., Moileyre, J.F., Bourret, P., Villermaux, J., 1982b. Cinétique macroscopique de la précipitation du sulfate de baryum en présente d'EDTA, J. Chim. Phys. 79, 719-724

Bernaux, L., 1987, Cinétique de précipitation du sulfate de baryum en milieu visqueux, rapport de microthèse, ENSIC-LSGC, Nancy

Bourne, J.R., Kozicki, F., Rys, P., 1981, Mixing and Fast Chemical Reaction I, Chem. Eng. Sci. 36, 1643.1648

Bourne. J.R. 1984. Micromixing Revisited. I.Chem. E. Symposium Ser. No. 87. 797-813

David, R., Villermaux, J., 1987 , Interpretation of micromixjng effects on fast consecutive competing reactions in semi-batch stirred tanks by a simple interaction model, Chem.-Eng. Comm. 54, 333-352

Eigen, M., De Maeyer, L., 1963, Technique of Organic Chemistry, Interscience, New York, 8. (2) , 895

Fields, S.D., Ottino, J.M., 1987, Effect of Segregation on the Course of Unpremlxed Polymerizations. AlChE Journal, 33, $959-975$

Flaschel, E., Raetz, E., Renken, A., 1983, Development of a Tubular Recycle Membrane Reactor for Continuous Operation with Solubles

Enzymes. In: Enzyme Technology, Lafferty, R.M. (ed.), Springer Verlag, Berlin, 285-295

Flaschel, E., Nguyen K.T., Renken, A., 1985, Improvement of Homogeneous Tubular Reactors Operated at Low Reynolds Number, Proc. 5 th

European Conference on Mixing, Würzburg, BHRA, The Fluid Engineering Centre Cranfieid, Beoford, 549-556

Langensiepen, H.-W., 1980, Verweilzeitverteilung von einphasig durchströmten Reaktoren mit maximal drei Stunden mitlerer Verweilzeit. Chem. Ing.-Tech. 52, 176-177

Metzdorf, C., Flaschel, E., Renken, A., 1986, Scale-up of Homogeneous Tubular Reactors Equipped with Internals. Proc. "Agitation Mécanique", PROGEC, Toulouse, 7-33-7-40

Nguyen, K.T., Flaschel, E., Renken, A., 1983, The Thermal Bulk Polymerization of Styrene in a Tubular Reactor. In: Polymer Reaction

Engineering, Reicher, K.-H., Geiseler, W. (ed.), Hanser Publ., München

Ranz, W.E., 1986, Analysis of Reaction Processes in Which Microscopic Heterogeneities Appear: Scale-up and Scale-down of Polymerization

Reactions. Ind. Eng. Chem. Fundam. 25, 561-565

Sulzer Brother Ltd., 1985, Static Mixing

Villermaux, J., 1983, Mixing in Chemical Reactors. Plenary Lecture ISCRE 7, ACS Symposium Series Vol. 226 (1983), 135-186

Villermaux, J., 1986, Micromixing Phenomena in Stirred Reactors, in Encyclopedia of Flujd Mechanics, Chapter 27, 708-771, Gulf Publishing

Company, Houston

Villermaux, J., David, R., 1983, Recent Advances in the Understanding of Micromixiry Phenomena in Stirred Reactors, Chem. Eng. Comm. 21 $105-122$ 